\title{
A ARTICUlaÇÃo ENTRE O LIVRO de HANS ROBERT JAUSS "A História da literatura com Provocação À TEORIA LiteráRIA", O CONTO DE LYGIA BOJUNGA "TCHAU" E AS NOVAS CONSTRUÇões FaMILIARES
}

\author{
THE ARTICULATION BETWEEN HANS ROBERT JAUSS' BOOK “THE \\ HISTORY OF LITERATURE WITH PROVOCATION TO LITERARY THEORY", \\ LYGIA BOJUNGA'S SHORT STORY "BYE" AND THE NEW FAMILY \\ BUILDINGS
}

DOI: 10.23926/RPD.2526-2149.2020.v5.n2.p889-900.id832

\section{Nádia Louise Dias de Sousa Freitas \\ Mestranda em Ensino (IFMT/UNIC) \\ Técnica em Assuntos educacionais no Instituto Federal de Mato Grosso (IFMT) \\ nadia.freitas@ifmt.edu.br}

\section{Degmar Francisco dos}

Anjos

Doutorado em Psicologia

Social

Docente do Instituto Federal da Paraíba (IFPB)

Docente do Programa de Pós-Graduação no Programa de em Ensino (IFMT/UNIC) degmaranjos@gmail.com
Resumo: Este artigo tem por objetivo realizar a articulação entre o objeto de pesquisa do Mestrado em Ensino, desenvolvido pelo Programa de Pós-Graduação da UNIC / IFMT relativo às novas formações familiares com o texto "A História da Literatura com Provocação à Teoria Literária", de Hans Robert Jauss (1994) e o conto "Tchau", de Lygia Bojunga (1984). A metodologia consiste em uma revisão bibliográfica comparativa, em que a autora retrata o quão doloroso para uma criança pode ser uma separação. Em uma articulação com a pesquisa, pode-se afirmar que as novas formações familiares impactam no processo formativo dos jovens, de forma a influenciar a visão dos estudantes e o papel dos professores que lidam diretamente com as novas gerações. $\mathrm{O}$ texto nos leva à reflexão quanto à importância de considerar as mudanças ocorridas na concepção de família, uma vez que esta reflete na construção do conhecimento do estudante e na vida.

Palavras-chave: Novas Formações Familiares. Professor. Estudante. Pais.

\begin{abstract}
This article aims to articulate the research object of the Master in Teaching, developed by the Graduate Program of UNIC / IFMT regarding new family formations with the text "The History of Literature with Provocation to Literary Theory", by Hans Robert Jauss (1994) and the short story "Tchau", by Lygia Bojunga (1984). The methodology consists of a comparative bibliographic review, in which the author portrays how painful a separation can be for a child. In articulation with the research, it can be said that the new family formations have an impact on the training process of young people, in order to influence the vision of students and the role of teachers who deal directly with new generations. The text leads us to reflect on the importance of considering the changes that occurred in the concept of family since it reflects in the construction of the student's knowledge and in life.
\end{abstract}

Keywords: New Family Formations. Teacher. Student. Parents. 


\section{INTRODUÇÃO}

A sociedade é mutável, ela oscila, varia, sofre mudanças e transforma a sua volta. E a família, sendo uma instituição social, também sofre transformações em sua estrutura à medida que a sociedade vai se modificando. Assim, entende-se que o conceito de família passe também por grandes alterações, o que faz com que hoje seja difícil traçar um perfil único da família brasileira.

É então que o século XXI apresenta-nos, para além da família tradicional, novas formações familiares, contrariando, inclusive, a visão até então existente de pater familias, na qual o poder familiar consistia em uma prática exclusivamente do homem. Dentre essas novas formações familiares, podem-se destacar algumas tendências importantes na estruturação das famílias: a diminuição do número de pessoas na família, o aumento de divórcios e recasamentos, casais homoafetivos, maior participação da mulher na manutenção econômica do lar e diferentes maneiras de compartilhar papéis nas funções parentais.

Os conceitos de família, inúmeros que são, encontra na Carta Magna, a Constituição Federal de 1988, para efeitos de proteção do Estado, a família como união estável entre homem e mulher ou qualquer dos pais e seus descendentes. Nessa nova conceituação de família, ao enfatizar a necessidade de proteção aos dependentes, a Constituição Brasileira reconhece o poder assimétrico entre os membros da família, deixando evidente que os direitos e deveres conjugais são exercidos igualmente pelo homem e pela mulher (Cap. VII, art. 226, 3Q, 4Q e $5 Q)$.

Goldani (1993) apresenta uma definição de família que chama de nuclear e que se relaciona diretamente à residência em um domicílio. Percebe-se que não se trata de um conceito privativo a um grupo de pessoas residentes em uma casa, como aponta a literatura demográfica sobre formação de arranjos domiciliares, mas trata que o âmbito de parentesco e de residência não necessariamente coincide, pois, as relações familiares podem se estender para além da unidade de residência (GOLDANI, 1993).

Dentre as outras tantas definições de família, vale ressaltar também Collange (1994) que, em seus estudos no final do século passado, menciona a impossibilidade em classificar e principalmente julgar os bons e maus "planos de família". São planos que ora procuram encontrar equilíbrio numa relação estável e fechada, voltada a si mesma para se fortalecerem contra agressões e mudanças de qualquer tipo, ora preferem uma família na qual se personalizam sem constrangimentos e sem obrigações, a fim de que seus integrantes possam 
usá-la basicamente para recarregar energias antes de saírem mais uma vez pelo mundo afora. (COLLANGE, 1994).

Nesse contexto, fica evidente que as transformações sociais, edificadas a partir da segunda metade do século XX e reelaboradas no início do século XXI, ressignificaram os laços familiares e seus impactos na vida de toda a sociedade. São famílias contemporâneas cuja estrutura é formada, além da tradicional formação mãe, pai e filhos, são formações também, mãe e filho, pai e filho, avós e neto, casais homoafetivos com filhos, e outros. Porém, algumas configurações parentais ainda sofrem preconceitos diante de interpretações emanadas de uma cultura tradicional de olhar perante a eventualidade em aceitar as diferentes famílias.

Há indícios de que as novas formações familiares, na contemporaneidade, interferem no modo de vida do jovem e consequentemente influencia no seu modo de ver o mundo e de tomar decisões nos mais diferentes aspectos de sua vida, uma vez que são crescentes os problemas da juventude deste século, como se pode observar quanto ao número de adolescentes e jovens que não obtém sucesso escolar, que não veem a escola com seriedade, que entram em depressão, que evadem da escola, que se refugiam nas drogas, enfim.

Nesse cenário de transformações, as novas gerações acabam por assumir responsabilidades que a realidade lhes apresenta, como muito bem evidencia o conto em análise, em que a menina Rebeca é vista pelos pais como alguém com quem podem desabafar, como se uma menina de dez anos fosse um adulto em miniatura. É uma personagem tratada com traços de uma pessoa mais velha e mais madura (ARIÈS, 1981).

E então, com todas as transformações e mudanças que vêm ocorrendo na sociedade e suas instituições, a instituição escolar não passaria ilesa. A escola consiste em um espaço de socialização onde tem início as primeiras relações de amizades e interações com diferentes culturas e classes sociais. Ela abriga uma comunidade escolar que manifesta uma gama de diversidade, da qual as famílias dos estudantes não estão imunes. Nesse sentido, a escola não pode deixar de se preparar para melhor acolher as diferentes configurações familiares, as quais, na contemporaneidade, manifestam-se com maior veemência, ao reivindicarem seu espaço na sociedade e também no ambiente escolar.

Diante do exposto, este artigo tem por objetivo realizar a articulação entre o objeto de pesquisa do Mestrado em Ensino, desenvolvido pelo Programa de Pós-Graduação da UNIC / IFMT relativo às novas formações familiares com o texto "A História da Literatura com Provocação à Teoria Literária", de Hans Robert Jauss (1994) e o conto "Tchau", de Lygia 
Bojunga (1984), no sentido de evidenciar a influência das novas formações familiares na vida escolar dos estudantes pertencentes às novas gerações.

\section{Metodologia}

A metodologia utilizada para a elaboração do artigo refere-se a uma pesquisa qualitativa bibliográfica comparativa, em consonância com as premissas de Bogdan e Biklen (1994). A pesquisa bibliográfica se configura como sendo o exame de materiais de natureza diversa, que ainda não receberam um tratamento analítico, ou que podem ser reexaminados, criando interpretações novas ou complementares, o que se aplica a situação em tela (LAKATOS, 1992).

\subsection{O CONTO}

"Tchau" conta a história de Rebeca, uma menina de 10 anos que experimenta os sentimentos conturbados da separação dos pais e a partida de sua mãe. É um momento em que Rebeca pensa que pode consolar o pai e convencer sua mãe a não partir. Em sua imaturidade, Rebeca não consegue entender os anseios da mãe por outro homem. Tanto o pai quanto a mãe falam para Rebeca sobre suas emoções. A mãe, em seu discurso, como se a criança pudesse entender para aceitar, expressa o fim do amor pelo marido, as sensações físicas proporcionadas pelo amante e a decisão já tomada de abandonar os filhos em nome dessa paixão. Rebeca ouve, espanta-se e tenta inutilmente dar sentidos à situação. Seguindo no mesmo caminho inconsequente da mãe, o pai abre-se com a filha contando do amor que ainda sente pela esposa e de sua insegurança em cuidar de duas crianças, ela e o irmãozinho Donatelo. É evidente que são assuntos além do entendimento de uma criança de dez anos.

Essa situação mexe tanto com o emocional de Rebeca que ela promete ao pai pedir à mãe que fique com eles. Depois da decepção em não conseguir seu intento, Rebeca escreve um bilhete ao pai contando o não cumprimento de sua promessa e a partida inevitável da mãe. Contudo, em sua singeleza, ela acredita que o fato de a mãe não ter conseguido levar a mala, faria com que ela voltasse logo para casa: “[...] escondi ela (a mala) embaixo da cama [...]" (p21).

O bilhete deixado ao pai revela a solução de uma filha, criança ainda, diante da crise a que foi apresentada, imposta mesmo, e sobre a qual não tem nenhum domínio. Esse é mais um daqueles conflitos que são apresentados a uma criança sem considerar sua jovem idade, e no caso de Rebeca, dez anos. O tratamento dado à figura infantil de Rebeca neste conto evoca um conceito que se tinha de infância antes da constituição das famílias burguesas e da consolidação 
da escola, em que a criança era vista como um adulto em miniatura, que participava de todos os assuntos da casa, inclusive de todas as brigas (ARIÈS, 1981).

Percebe-se que neste conto, tudo o que envolve a filha, a mãe e o pai transitam em um limite complexo de fragilidade. Quando a mãe diz que quer separar do pai, que não dá mais para conviverem, de uma forma bastante insensata, essa mãe revela fatos que aos ouvidos da criança, seriam inaudíveis. : “- Não sei; [...], essas coisas a gente nunca sabe direito, mas eu sei que eu fui me sentindo sozinha... vazia... vazia de amor. Amor assim [...] assim de um homem. É claro que isso não tem nada a ver com o amor que eu sinto por você” (p. 13).

Neste ponto entram reflexões: como ou de que forma uma criança de dez anos poderia compreender por “amor de um homem”? E a mãe, em suas revelações emocionais para a filha, continua declarando as sensações e contradições de sua paixão pelo novo amor, desconsiderando por completo a pouca idade de Rebeca. Em outros momentos de seu caloroso discurso, a mãe faz revelações de completa insensatez revelando que tudo o que pratica durante o dia, desde o cuidado com os filhos e com a casa, ela o realiza como se estivesse dormindo, pois, sonha com ele, e que é ele o seu único pensamento, diuturnamente. É a definição da paixão. E como uma criança poderia entender paixão? Tomada por esse sentimento, sua mãe deixa os filhos, a pedido do próprio amante e vai para a Grécia. Ao final de seu diálogo com a mãe, a menina faz a seguinte observação: "E ainda mais essa! Com tanto homem no Brasil [...]" (p. 14).

Assim, de tudo o que ouviu, Rebeca apenas observa os dois fatos concretos: a separação dos pais e a possível partida de sua mãe. Os detalhes do sentimento materno, ao que parece, não foram significativos para a personagem. Tais aspectos somente evidenciam as teias que embaraçam a vida de crianças, adolescentes e jovens a partir das formações familiares que fogem ao modelo tradicional.

Episódios como o abandono do lar e a forma com que a mãe explica a situação para a filha, são aspectos que chamam a atenção na narrativa de Lygia Bojunga. No Brasil, muito recentemente, a justiça sancionou a lei da guarda compartilhada, mas, de qualquer forma, na grande maioria das separações, os filhos ficam com a mãe, perpetuando uma tradição construída ao longo da história da humanidade.

No contexto de gênero, a percepção de Simone de Beauvoir (2001), é a de que a biologia da mulher é a sua maior inimiga, uma vez que é em função da maternidade que o sexo feminino, por um longo tempo, teve seu espaço restrito ao lar. A mãe de "Tchau" foge à regra estabelecida e sofre a pressão emocional, social e jurídica, como adverte o pai, quando diz a ela que não é 
ele quem está abandonando a família e que com o abandono do lar, da família, de tudo, a lei ficará ao lado dele. Diz ainda que ela deva escolher entre o novo amor e seus filhos (p.16).

No conto, o personagem pai apela para a sensibilidade materna, arrisca impor-lhe o medo de não mais ver seus filhos. Um apelo que remete à uma construção sócio-histórica e econômica de um espaço feminino restrito à sua função de mãe. Primeiro nas tribos primitivas, quando a mulher, por estar sempre grávida, necessitava ficar em casa para cuidar dos filhos já nascidos e do que estava por nascer. Depois, com o surgimento da burguesia, originada pela Revolução Francesa, a figura feminina permanece restrita ao lar, porque a ela caberia acompanhar a educação de seus filhos.

Segundo Simone de Beauvoir (2001), ser mãe determina na mulher uma escolha para ser mãe, e não exatamente o instinto de anulação de ser mulher. É um mito acreditar que a mulher se anula por instinto. "A fecundidade absurda da mulher a impedia de participar ativamente do crescimento dos recursos ao passo que ela criava novas necessidades" (BEAUVOIR, 2001, 1. vol., p. 34-46).

Quando o pai faz a ameaça de separar a mãe definitivamente dos filhos, é somente o desespero que toma conta de seu emocional, por medo de perder a mulher amada. Nesta fase do conto, o homem manifesta-se como um ser ferido pela troca da esposa, sem conseguir perceber, refletir sobre o motivo pelo qual a esposa está agindo dessa forma (p18).

É neste momento que Rebeca, infantilmente, acredita que resolverá tudo só pedindo à mãe que fique. E então, ao analisar a importância dos contos de fadas para o amadurecimento infantil, Bettelheim (1980) explica que a dor é imprescindível para que o ser humano sinta-se existente. A criança necessita passar por todas as etapas da vida confrontando-se verdadeiramente com os obstáculos que surgirem, mesmo aqueles tão injustos. Será assim que a criança crescerá forte o suficiente para se sair vitoriosa diante da vida (BETTELHEIM, 1980, p14).

Na Literatura Infanto-Juvenil brasileira, este conto é um dos primeiros a tratar da temática da separação de um casal a partir da saída de casa da mãe. A personagem da mãe é a de uma pessoa solitária, construída na década de 80, que se entrega a uma alucinada paixão, que deixa os filhos com o marido e acaba com um casamento que a fazia infeliz. Na leitura deste conto, com os olhos tradicionais, a análise para a culpabilidade do término da relação recai na figura materna.

Entretanto, é importante perceber que a mulher, antes de ser mãe, é um ser humano que se dispõe a tomar decisões que contrariam aquilo que está estabelecido historicamente, no caso 
a maternidade. Nesta narrativa, Lygia Bojunga lembra que a mulher é um ser emocional que não se limita à maternidade, e mostra que uma criança possui seus próprios meios para superar a separação dos pais, e que essa realidade é algo cada vez mais constante que enfrentarão crianças, adolescentes e jovens diante das novas formações familiares.

\subsection{Os Dados - O Elemento Marcante das Novas Formações Familiares}

Nesse atual contexto das novas construções familiares, em pleno século XXI, ainda encontramos a não compreensão e o comportamento preconceituoso de muitas pessoas em relação a tudo aquilo que não está dentro dos padrões do normal, do tradicional. Nesse sentido, se pensarmos na personagem da mãe do conto "Tchau”, que abandona a família por uma insana paixão, em meio aos anos oitenta, sua atitude é bastante incoerente e inaceitável. Como ainda hoje, àquela sociedade já repudiava a mulher com coragem de se entregar incondicionalmente ao amor de um amante.

Tradicionalmente, o sexo feminino sempre esteve atrelado ao espaço do lar. Segundo Margaret Mead (2003), nas tribos primitivas a organização era feita em dois espaços: um espaço fora de casa, destinado ao homem que tinha a obrigação de buscar o alimento para a família e manter financeiramente filhos e esposa; e o espaço de dentro de casa, destinado à mulher com a obrigação de cuidar da prole e preparar os alimentos.

Essa estrutura familiar é a que caracteriza família na maior parte das culturas sociais. E então a Revolução Francesa traz a burguesia e com ela, a mulher como responsável pela educação dos filhos e pela organização do lar. Estudiosos e suas pesquisas recentes demonstram que a mulher do século XXI, apesar da conquista no espaço profissional, continua vivendo a dupla jornada, ou seja, trabalhando fora e dentro do lar. Nem sempre esse trabalho significa serviços domésticos, mas a organização de outros aspectos, como o cuidado em manter a casa abastecida de alimentos, cuidados com questões escolares e emocionais dos filhos, entre outros. E então reiteramos a ousadia de Lygia Bojunga, a autora que na década de 80 deu vida a um tema bastante delicado e ainda muito mal resolvido atualmente: o abandono do lar por uma mãe apaixonada pelo amante.

\section{A ANÁLISE DOS DADOS - AS ARTICULAÇÕES POSSÍVEIS}

Jauss (1994), em sua obra “A História da Literatura como provocação à Teoria Literária", busca transpor o abismo relativo aos modelos existentes no que se refere à literatura, uma vez que o autor não vê uma verdadeira história da literatura que conjugue com a 
historicidade das obras quanto com as suas qualidades estéticas, sem deixar que uma prevaleça à outra ou a suprima.

Para efetivar tal ideia, Jauss (1994) debate com duas correntes literárias antagônicas: o marxismo e o formalismo. São escolas que para ele se mostram falhas para englobar o desafio de construir uma história literária. Nesse aspecto, o autor apresenta uma proposta, partindo de uma falha observada nos dois espaços críticos, até porque, para o autor, uma história não é aceita passivamente pelo leitor. O leitor pode interpretar e perceber outros significados a partir da sua própria experiência individual e cultural.

Segundo Jauss (1994), devem-se considerar os critérios da recepção, os efeitos produzidos pela obra nos leitores. São esses efeitos que devem ser a meta principal de quem produz uma obra e da própria obra em si.

Nessa conjuntura, Jauss (1994) conceitua um novo leitor, que está longe do formalismo, que acredita no sentido direto do texto, que solicita independência textual no que se refere ao decurso temporal. Esse leitor está longe também do marxismo que o transforma na mesma concepção do autor, numa classe social. Na compreensão de Jauss (1994), o leitor e sua experiência estética apropriam-se de uma postura única de como se alicerçar metodologicamente e reiterar a história da literatura.

Atualmente, a Literatura Infanto-Juvenil, em consonância com o entendimento de Jauss (1994), tem se empenhado em aprimorar temas relevantes para a realidade de jovens leitores com a clara intenção de atender a esse público. São temas que abarcam violência urbana, morte, abandono, crianças moradoras de rua, amizade e conflitos familiares. No cenário específico do conto de Lygia Bojunga, a autora aborda temas bastante importantes às crianças e aos jovens: a própria infância, o abandono, a solidão, os ciúmes, a paixão, o amor, a amizade, para citar apenas alguns.

Na prática, a proposta que se fez diante da nova tendência que se iniciou no Brasil, na década de 80, com a chamada Literatura Realista, em oposição à Literatura Fantástica, foi oferecer ao público algo com essa produção, que possibilitasse pensar a sua realidade a partir da literatura, com personagens que vivenciassem situações muito próximas às que esses leitores enfrentavam no mundo real, com a finalidade de que esses leitores pudessem resolver os conflitos pelos quais estariam passando.

Não se pode deixar de sobrelevar que a obra literária era transposta pela capacidade de modificar pessoas e suas convenções, e que esse poder passou a ser mais contundente depois do período romancista, no século XVIII, crédito que chegou ao século XIX, quando a palavra 
ainda era considerada por seu poder ilimitado. Dentro desse contexto, o exercício da Literatura representava uma condição sine qua non para a tradução da realidade, com um impressionante talento para espelhar o mundo e seus contornos.

Nos dias de hoje, a percepção da Literatura busca, em similaridade com o pensamento de Lajolo (2002), uma contingência da significação temporária, no momento em que transforma esse temporário em permanente. A arte literária, então, torna-se aqui o ato real, concebível à medida que permite o encontro de escritor e leitor sem que haja qualquer comunicação anterior entre eles, acordando valores, representações, e outros (LAJOLO, 2002).

É evidente que o conceito de literatura é entendível aqui como uma questão de leitura, entendendo-a como um processo de construção de sentidos. Antonio Candido (1973) reitera que a Literatura tem o poder de ratificar a humanidade do homem, quando da sua função de atender uma necessidade absoluta de fantasia, colaborando com a construção da personalidade e ser, ainda, uma forma de sentir o sujeito e o mundo (CANDIDO, 1973).

Na prática, o que constatamos na Literatura Infanto-Juvenil brasileira é um número crescente de autores que buscam abarcar em seus livros as vozes dos jovens leitores, suas angústias, suas preocupações, seus problemas. Porém, já não mais com o olhar do adulto, como durante décadas impôs suas normas de conduta e valores, com a intenção exclusiva de moralizar seus sentimentos e suas ações.

$\mathrm{Na}$ tentativa da construir um texto de articulação entre o livro de Jauss (1994), o conto “Tchau”, de Lygia Bojunga (2002) e o objeto de investigação dos mestrandos em ensino pelo Programa de Pós-Graduação da UNIC/IFMT, cujo tema versa sobre as novas formações familiares e seus impactos no processo formativo dos jovens por meio da visão da figura paterna, dos próprios jovens estudantes e dos professores, em um contexto histórico, podemos afirmar que a família se apresenta como o primeiro grupo social presente no estado de natureza. Rousseau (1983) afirma que a família é a mais antiga de todas as sociedades e a única natural.

$\mathrm{Na}$ narrativa "Tchau", a autora constrói um personagem infantil que fala e que vive situações semelhantes a uma realidade que o jovem leitor também pode viver ou pode estar vivendo. E aqui a referência são as tramas familiares. A sensibilidade consiste na marca da narrativa "Tchau", conto da obra homônima, lançada por Lygia Bojunga no ano de 1984.

Sabe-se que a família interfere no desenvolvimento das características individuais de seus membros, no seu modo de pensar e de viver. Partindo do princípio de que a constituição protege o núcleo familiar, todas as formações familiares serão objeto de proteção constitucional: a família homoafetiva, a consanguínea, a concubinária, entre outras. 
A forma como a narrativa do conto "Tchau" se desenvolveu, o esforço empregado para mostrar por meio das relações sociais e familiares que marcam a obra de Lygia Bojunga, tem a intenção de surpreender o leitor e desafiá-lo, desconstruindo padrões básicos estabelecidos pela história social das relações.

\section{CONSIDERAÇÕES FINAIS}

O conto "Tchau" trata de um tema bastante presente na sociedade contemporânea que é a separação matrimonial. Esse conto narra a separação dos pais, a partida da mãe e os filhos menores que ficam com o pai. É a configuração das novas formações familiares, principalmente se as considerarmos, em especial, após a década de 80, quando a Constituição Federal do Brasil marca a mudança de concepção de família, uma vez que graças aos preceitos legais da Carta Magna de 1988, a família pode ser constituída por pessoas que moram no mesmo lugar, e que tem como objetivo construir um lar, com base somente nos vínculos afetivos, independente de matrimônio.

A separação na narrativa "Tchau" é vista, principalmente, pelo olhar feminino através dos sentimentos ingênuos da criança de dez anos, Rebeca, uma garotinha que vivencia toda essa transformação social, assim como também através dos sentimentos da mãe que ora é dor, ora é hesitação, ora é decisão e partida. A criança é a protagonista da história que permite ao leitor conhecer o sofrimento que causa o desgaste emocional do casal, a fraqueza do pai, que busca esquecer o problema na bebida, a partida da mãe que passará a formar uma nova construção familiar.

No conto não encontramos a primazia do adulto sobre a criança, pelo contrário, existe uma inversão dos papéis familiares: os adultos tentam encontrar na criança o apoio de que precisam. E então, sem aceitar e sem entender essa situação, a criança Rebeca torna-se interlocutora da mãe e acolhe o pai em sua dor.

Diante do que fora aqui exposto mediante pesquisa comparativa que teve por base analítica a articulação entre o objeto de pesquisa do Mestrado em Ensino, desenvolvido pelo Programa de Pós-Graduação da UNIC / IFMT relativo às novas formações familiares com o texto "A História da Literatura com Provocação à Teoria Literária", de Hans Robert Jauss (1994) e o conto “Tchau”, de Lygia Bojunga (1984), é possível perceber que as modernas formações familiares interferem na vida das novas gerações de forma a intervir na trajetória escolar dos jovens. 
Fica evidente que as novas formações familiares na contemporaneidade interferem no modo de vida do jovem e consequentemente influencia no seu modo de ver o mundo e de tomar decisões nos mais diferentes aspectos.

Considerando que nos tempos atuais, o número de jovens que evadem da escola, entram em depressão e chegam até mesmo a cometer suicídios, tem aumentado de forma assustadora, se faz importante que a escola e a família estejam atentas às mudanças sociais que alteram costumes e contribuem para uma nova cultura de vida escolar para a juventude.

Partindo desta constatação, os professores acabam por perceber e assumir mais esse desafio. É dentro da escola que se manifestam os problemas dos jovens no enfrentamento com a realidade, e onde eles demonstram de forma pacífica ou não a solução que encontram para conviver em sociedade.

\section{REFERÊNCIAS}

ARIÈS, Philippe. História social da criança e da família. $2^{\text {a }}$ ed., Rio de Janeiro: LTC, 1981. BETTELHEIM, Bruno. A psicanálise dos contos de fada. Trad. de Arlene Caetano. Rio de Janeiro: Paz e Terra, 1980.

BEAUVOIR, Simone de. O segundo sexo: fatos e mitos. Trad. Sérgio Millet. Rio de Janeiro: Nova fronteira, 2001.

BOGDAN, Robert; BIKLEN, Sari. Investigação Qualitativa em educação: uma introdução à teoria e aos métodos. Porto, Portugal: Porto Ed., Coleção Ciências da Educação, 1994.

BRASIL. Constituição (1988). Constituição da República Federativa do Brasil: promulgada em 5 de outubro de 1988. 47. ed. Brasília: Edições Câmara, 2015.

CANDIDO, Antonio. Literatura e Sociedade. São Paulo: Companhia Nacional, 1973.

COLLANGE, Christiane. Defina uma família. Trad. Mário Fondelli. Rio de Janeiro: Racco, 1994.

GOLDANI, Ana Maria. As famílias no Brasil contemporâneo e o mito da desestruturação. Cadernos Pagu, 1993, n.1.

JAUSS. Hans Robert. A História da Literatura com Provocação a Teoria Literária. Editora Ática - série Tams, volume 36, São Paulo, 1994.

LAJOLO, Marisa. Do mundo da leitura para a leitura do mundo. São Paulo: Ática, 2002.

LAKATOS, Maria Eva. MARCONI, Maria de Andrade. Metodologia do Trabalho Científico. 4 ed/. São PAulo. Revista e Ampliada. Atlas, 1992.

MEAD, Margaret. Sexo e temperamento. São Paulo: Editora Perspectiva, 2003. 
Revista Prática Docente (RPD)

ISSN: 2526-2149

NUNES, Lygia Bojunga. Tchau. Rio de Janeiro: Agir, 1984.

ROUSSEAU, Jean-Jacques. Do Contrato Social. São Paulo: Abril Cultural, 1983. Série Os Pensadores.

Recebido em: 12 de maio de 2020.

Aprovado em: 28 de agosto de 2020. 